\title{
Extracorporeal membrane oxygenation for management of iatrogenic distal tracheal tear
}

\author{
Robert B. Hawkins, MD, MSc, ${ }^{a}$ Eryn L. Thiele, MD, ${ }^{\mathrm{b}}$ Julie Huffmyer, MD, ${ }^{\mathrm{b}}$ Allison Bechtel, MD, ${ }^{\mathrm{b}}$
}

Kenan W. Yount, MD, MBA, ${ }^{\mathrm{a}}$ and Linda W. Martin, MD, MPH, ${ }^{\mathrm{a}}$ Charlottesville, Va

\footnotetext{
From the ${ }^{\mathrm{a}}$ Division of Thoracic and Cardiovascular Surgery and ${ }^{\mathrm{b}}$ Department of Anesthesiology, University of Virginia, Charlottesville, Va.

Disclosures: Dr Yount reported receiving professional fees from Edwards Lifesciences. All other authors reported no conflicts of interest.

The Journal policy requires editors and reviewers to disclose conflicts of interest and to decline handling or reviewing manuscripts for which they may have a conflict of interest. The editors and reviewers of this article have no conflicts of interest.

Accepted for the 42nd Annual Meeting of the Society of Cardiovascular Anesthesiologists, West Palm Beach, Florida, April 18-22, 2020 (canceled for COVID-19).

Received for publication July 14, 2020; revisions received July 14, 2020; accepted for publication July 28, 2020; available ahead of print Aug 4, 2020.

Address for reprints: Linda W. Martin, MD, MPH, University of Virginia Health System, PO Box 800679, Charlottesville, VA 22908 (E-mail: 1m6yb@virginia.edu).

JTCVS Techniques 2020;4:389-91

2666-2507

Copyright (C 2020 The Authors. Published by Elsevier Inc. on behalf of The American Association for Thoracic Surgery. This is an open access article under the CC BY-NC-ND license (http://creativecommons.org/licenses/bync-nd/4.0/).

https://doi.org/10.1016/j.xjtc.2020.07.020
}

Tracheobronchial injuries during intubation are rare, with an incidence of $0.005 \%$; thus, diagnosis requires a high index of suspicion. ${ }^{1}$ Risk factors include female sex, age older than 65 years, and emergency intubation. ${ }^{1,2}$ Temporal correlation with respiratory failure, subcutaneous emphysema, and pneumothorax/pneumomediastinum should prompt evaluation of the tracheobronchial tree. Bronchoscopy is instrumental for diagnosis and management, including placement of the endotracheal tube distal to the injury before definitive intervention. The following case highlights the unique airway, ventilatory, and anesthetic concerns associated with a severe distal tracheal tear in the setting of underlying lung injury.

\section{CASE REPORT}

A 53-year-old female patient presented to an outside hospital with acute respiratory failure from adenovirus. Multiple intubation attempts with direct laryngoscopy preceded successful intubation using a video laryngoscope. She immediately developed subcutaneous emphysema and increasing ventilatory requirements. Bronchoscopy demonstrated a distal tracheal injury, and she was transferred emergently for escalation of care.

Upon arrival, she had full-body, extreme subcutaneous emphysema (Figure 1). Despite maximal mechanical ventilation, her initial arterial blood gas revealed a pH 6.94, arterial carbon dioxide tension $166.8 \mathrm{~mm} \mathrm{Hg}$, and arterial oxygen tension $98.5 \mathrm{~mm} \mathrm{Hg}$. She was emergently taken to the operating room and placed on percutaneous femoral-femoral, veno-venous extracorporeal membrane oxygenation (ECMO). Bronchoscopy revealed a 3-cm,

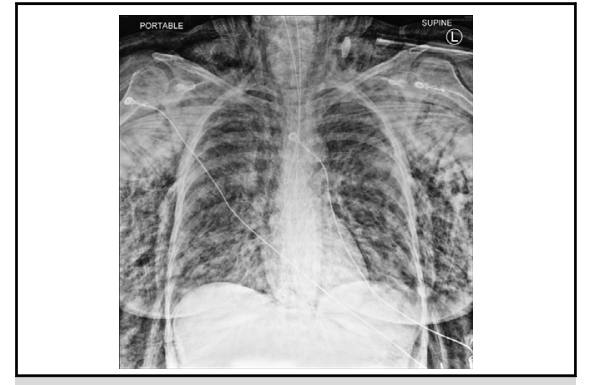

Chest radiograph with extensive subcutaneous emphysema due to tracheal laceration.

\section{CENTRAL MESSAGE \\ For tracheal injury with underly- ing lung disease, early institution of veno-venous ECMO allows for safe tracheal repair and low postoperative airway pressures with the potential for complete recovery.}

See Commentaries on pages 392 and 393.

full-thickness (grade IIIA) membranous tracheal tear terminating $1 \mathrm{~cm}$ above the carina (Figure 2). ${ }^{3}$ A flexible wirereinforced endobronchial tube was advanced past the tracheal tear. Upper endoscopy revealed no esophageal injury. Bilateral chest wall venting incisions (blowholes) were made and vacuum-assisted closure devices placed. ${ }^{4}$

After resuscitation, confirmation of intact neurologic status and normalization of acid-base status, the patient returned to the operating room 12 hours later for tracheal repair via right posterolateral muscle-sparing thoracotomy. The endotracheal tube could not be positioned for lung isolation, so it was withdrawn to the mid-trachea and ventilation paused. The membranous trachea was repaired with interrupted absorbable sutures, buttressed with an intercostal muscle flap, and the endotracheal tube positioned proximal to the repair. Frequent bronchoscopy confirmed appropriate positioning, healing, and pulmonary toilet. She was transitioned to a dual-stage internal jugular cannula to allow for mobilization once resolution of subcutaneous emphysema allowed access to her neck. Anticoagulation was achieved with a partial thromboplastin 

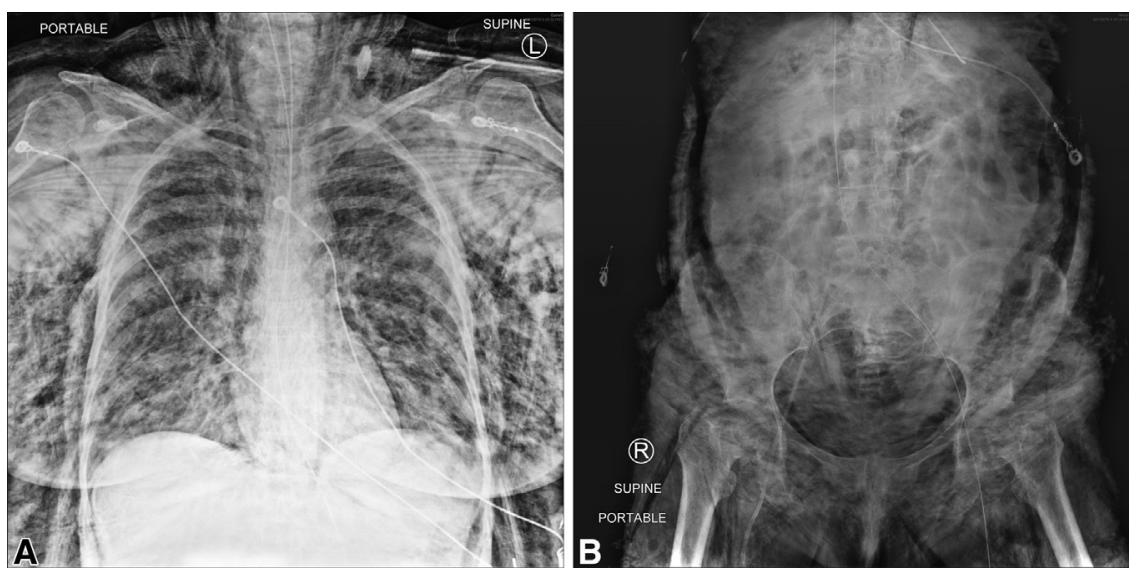

FIGURE 1. A, Chest and B, abdominal radiographs with extensive subcutaneous emphysema creating streak artifact taken upon arrival to the emergency department after transfer for tracheal laceration management.

time-guided unfractionated heparin infusion. On postoperative day 9, she underwent thoracoscopic evacuation of a right-sided hemothorax and open tracheostomy with a flexible, wire-reinforced 7-mm tracheostomy tube to ensure positioning above the tracheal repair. Peak airway pressures

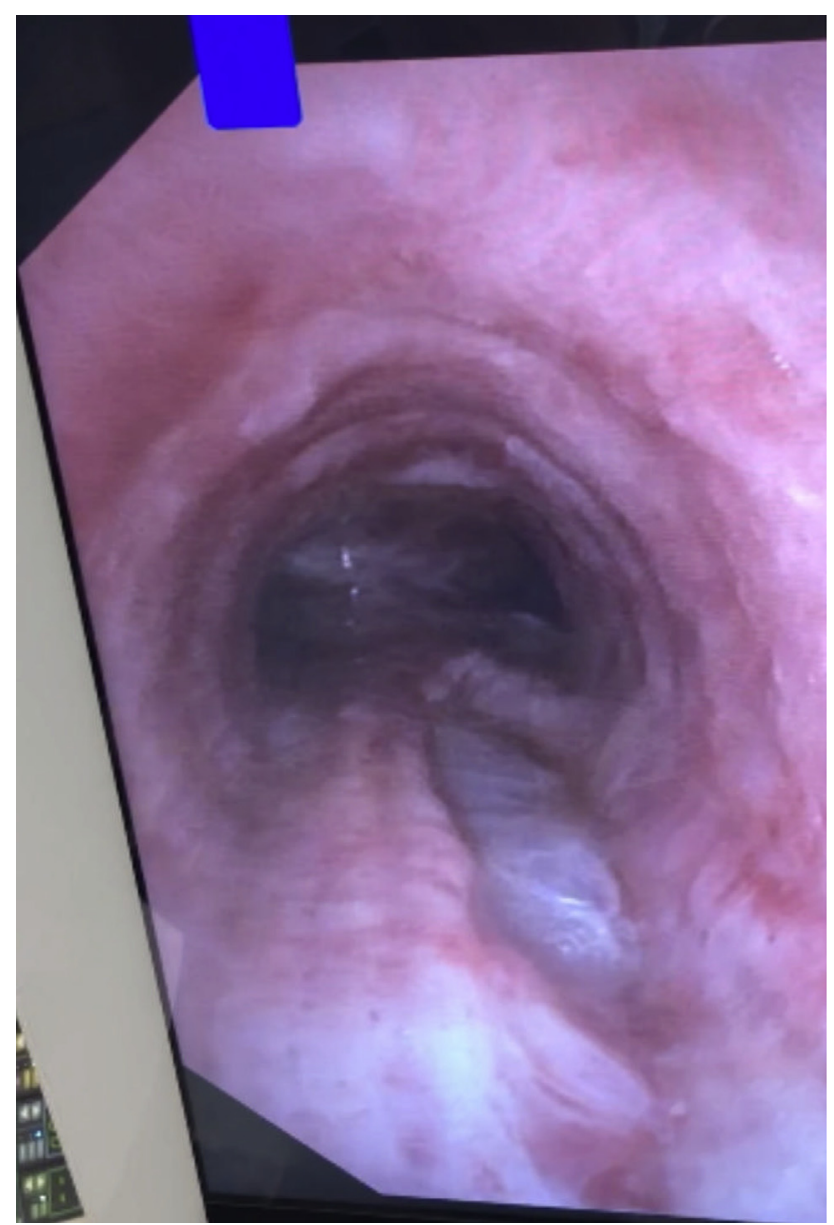

FIGURE 2. Endotracheal photograph of full-thickness tracheal laceration in the posterior membranous trachea with the esophagus visualized underneath. were initially restricted to 14.7 mbar. Due to extremely poor lung compliance, initial tidal volumes were 0 to $6 \mathrm{~mL}$ with continuous positive airway pressure for additional oxygenation required despite ECMO. She was weaned off ECMO and decannulated on day 14.

Her postoperative course was complicated by a perforated duodenal ulcer requiring Graham patch repair and deep vein thromboses requiring inferior vena cava filter placement. Her tracheostomy was decannulated on hospital day 48 , and she was discharged home on day 51 . She was ambulating independently, eating a regular diet, and breathing comfortably on room air at the time of discharge and is doing well at 8-month follow-up. This manuscript was exempt from institutional review board approval.

\section{DISCUSSION}

In this patient with multiple risk factors for tracheal injury, female sex and emergency intubation, the likely culprit was a rigid stylet. Rapid flexible bronchoscopy enables placement of the endotracheal tube past the injury. Double-lumen endotracheal tubes should be avoided due to their size and rigidity. Use of wire-reinforced endobronchial tubes can help with angulated bronchial anatomy. The depth of this injury with visible esophagus demonstrates the importance of esophagoscopy.

The role of ECMO support for tracheal complications comes from case reports of tracheal stenosis, massive hemoptysis, and tracheal injury not related to intubation. ${ }^{3,5-7}$ Unique to this case, the underlying lung disease (adenovirus pneumonia) and distal injury necessitated emergent ECMO to correct severe hypercarbia and acidosis. Femoral-femoral veno-venous access allows for fast cannulation without ultrasound or transesophageal echocardiography. Although recirculation can be a limitation, it should be sufficient to pause ventilation during the tracheal repair if alternative ventilation strategies cannot be used. If possible, use of a dual-stage cannula can help 
facilitate ambulation while on ECMO ${ }^{8}$ Continuation of ECMO support after tracheal repair permits low-pressure ventilation in the setting of underlying pulmonary processes. It is prudent to consider decannulation only after sufficient healing and improvement in airway compliance allowing for safe ventilation above the repair. However, these benefits should be weighed against the risks of ECMO, most notably bleeding and thrombosis, as occurred in this patient. In the setting of underlying lung disease or injury, early institution of veno-venous ECMO should be considered to allow for safe tracheal repair and postoperative ventilation with low airway pressures.

\section{References}

1. Minambres E, Buron J, Ballesteros MA, Llorca J, Munoz P, Gonzalez-Castro A. Tracheal rupture after endotracheal intubation: a literature systematic review. Eur J Cardiothorac Surg. 2009;35:1056-62.
2. Singh P, Wojnar M, Malhotra A. Iatrogenic tracheal laceration in the setting of chronic steroids. J Clin Anesth. 2017:37:38-42.

3. Grewal HS, Dangayach NS, Ahmad U, Ghosh S, Gildea T, Mehta AC. Treatment of tracheobronchial injuries: a contemporary review. Chest. 2019;155: 595-604.

4. Son BS, Lee S, Cho WH, Hwang JJ, Kim KD, Kim DH. Modified blowhole skin incision using negative pressure wound therapy in the treatment of ventilatorrelated severe subcutaneous emphysema. Interact Cardiovasc Thorac Surg. 2014;19:904-7.

5. Fermin L, Arnold S, Nunez L, Yakoub D. Extracorporeal membrane oxygenation for repair of tracheal injury during transhiatal esophagectomy. Ann Card Anaesth. 2017;20(suppl):S67-9.

6. Son BS, Cho WH, Kim CW, Cho HM, Kim SH, Lee SK, et al. Conservative extracorporeal membrane oxygenation treatment in a tracheal injury: a case report. $J$ Cardiothorac Surg. 2015;10:48.

7. Sian K, McAllister B, Brady P. The use of extracorporeal membrane oxygenation therapy in the delayed surgical repair of a tracheal injury. Ann Thorac Surg. 2014; 97:338-40.

8. Lehr CJ, Zaas DW, Cheifetz IM, Turner DA. Ambulatory extracorporeal membrane oxygenation as a bridge to lung transplantation: walking while waiting. Chest. 2015;147:1213-8. 